\title{
RECENT PROGRESS IN THE CHEMISTRY AND BIOCHEMISTRY OF RIFAMYCINS
}

\author{
P. SENSI \\ Lepetit Research Laboratories, Milan, Italy
}

\begin{abstract}
The availability of a large number of natural and semisynthetic rifamycins made it possible to derive a clear relationship between structural features and activity against the target enzyme, the bacterial DNA-directed RNA polymerase (DDRP). Recent data are reported on the conformation of the active molecule in solution and on the Hansch approach for quantitative correlation between the in vitro antibacterial activity of several rifamycins and their lipophilicity.

Some semisynthetic rifamycins were found to have a limited activity on the DDRP of rifampicin-resistant bacteria and of cytoplasmic DNA-viruses and on the RNA-directed DNA polymerase (RDDP) of oncogenic RNA viruses, but up-to-now there is no clear indication of the essential structural requisites for these activities.

The biosynthetic pathways leading from acetate to propionate units to the ansamycins (rifamycins, tolipomycins, streptovaricins) are reviewed. The suggestion is made that utilization of different producing strains, their mutants, mixed fermentations and other techniques could yield a large number of new natural ansamycins to be tested on a battery of polymerizing enzymes (DDRP and RDDP).
\end{abstract}

\section{INTRODUCTION}

The rifamycins are a family of closely related antibiotics of remarkable interest because of their structure, biogenesis, mechanism of action and therapeutic efficacy. They also offer a challenging field of research on molecular manipulation and on structure-activity relationships. The rifamycins are the first natural compounds to be assigned a structure with an aromatic moiety spanned by an aliphatic bridge; therefore they are ansa compounds, according to the definition of Lüttringhaus and Gralheer ${ }^{1}$. At present several natural products with ansa structure are known (Table 1). Some of them are metabolites of micro-organisms of the order Actinomycetales, for which Prelog suggested the general name of 'ansamycins' ${ }^{2}$. Others have been isolated from higher plants. It is noteworthy that all ansa compounds so far described possess interesting biological properties. 


\section{P. SENSI}

Table 1. 'Ansa' natural products

\begin{tabular}{|c|c|c|}
\hline Name & Origin & Biological activities \\
\hline Rifamycins & $\begin{array}{l}\text { (Streptomyces } \\
\text { mediterranei) } \\
\text { Nocardia } \\
\text { mediterrenea }\end{array}$ & $\begin{array}{l}\text { Antibacterial (Gram-positive, } \\
\text { Gram-negative and Mycobacteria) } \\
\text { [Antiviral] } \\
\text { [Inhibitors of 'reverse transcriptase'] }\end{array}$ \\
\hline Streptovaricins & $\begin{array}{l}\text { Streptomyces } \\
\text { spectabilis }\end{array}$ & $\begin{array}{l}\text { Antibacterial (Gram-positive, } \\
\text { Gram-negative and Mycobacteria) } \\
\text { [Antiviral] } \\
\text { [Inhibitors of 'reverse transcriptase'] }\end{array}$ \\
\hline Tolypomycins & $\begin{array}{l}\text { Streptomyces } \\
\text { tolypophorus }\end{array}$ & Antibacterial \\
\hline Geldanamycin & $\begin{array}{l}\text { Streptomyces } \\
\text { hygroscopicus }\end{array}$ & Antiprotozoal \\
\hline $\begin{array}{l}\text { Maytansine } \\
\text { Maytanbutine } \\
\text { Maytanprine }\end{array}$ & $\begin{array}{l}\text { Maytenus ovatus } \\
\text { Maytenus } \\
\text { buchananii }\end{array}$ & $\begin{array}{l}\text { Antileukaemic, antitumour } \\
\text { Antileukaemic, antitumour }\end{array}$ \\
\hline $\begin{array}{l}\text { Colubrinol } \\
\text { Colubrinol acetate }\end{array}$ & Colubrina texensis & $\begin{array}{l}\text { Antileukaemic, antitumour } \\
\text { Antileukaemic, antitumour }\end{array}$ \\
\hline
\end{tabular}

\section{ORIGIN, STRUCTURE AND BIOLOGICAL ACTIVITIES OF RIFAMYCINS}

The rifamycins ${ }^{3}$ are secondary metabolites synthesized by a micro. organism originally considered to belong to the genus Streptomyces ${ }^{4}$ and subsequently reclassified as a Nocardia ${ }^{5}$ ( $N$. mediterranea, Margalith and Beretta). In normal fermentation conditions the strain produces at least five active substances, designated rifamycin A, B, C, D, E, which constitute the rifamycin complex ${ }^{6}$. Only rifamycin B was isolated as a crystalline pure substance, and it is practically the only component of the rifamycin complex produced when sodium diethylbarbiturate is added to the fermentation media?.

Rifamycin B has the unusual property that, in aqueous oxygenated solutions, it tends to change spontaneously into other products with higher antibacterial activity (rifamycin $\mathrm{O}$, rifamycin $\mathrm{S})^{8,9}$. The structure of rifamycin B (and of the related compounds involved in the 'activation' process) has been elucidated by chemical ${ }^{10,11}$ and $\mathrm{x}$-ray crystallographic methods ${ }^{12}$ (Figure 1). Rifamycin SV, obtained by mild reduction from rifamycin S, was the first member of the rifamycin family to find clinical application ${ }^{13}$.

Other rifamycins have been isolated from the fermentation broths of $N$. mediterranea or its mutants and their structures elucidated: rifamycin $\mathrm{Y}^{14,15}$, rifamycin $\mathrm{L}^{16}, 27-O$-demethylrifamycin $\mathrm{B}, 27-\mathrm{O}$-demethylrifamycin $\mathrm{SV}$ and its deacetyl derivative ${ }^{17}$.

Isolation of Streptomyces or Nocardia strains producing rifamycin $\mathrm{O}$ has been reported by Japanese researchers ${ }^{18}$. A mutant able to produce directly rifamycin SV has been obtained ${ }^{19}$ and a Nocardia strain isolated by Australian researchers also possesses the same property ${ }^{20}$. Besides the 


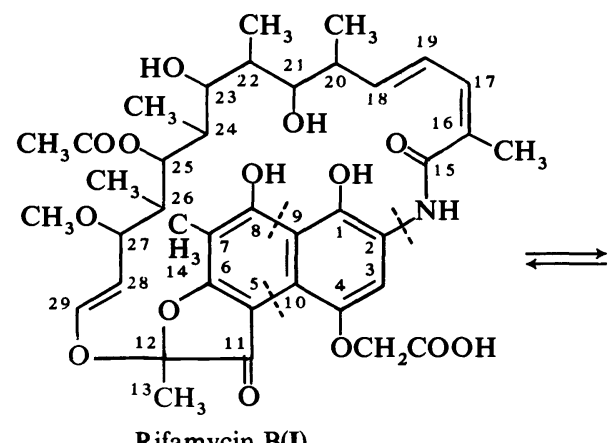

Rifamycin B(I)<smiles>Oc1cc(I)c(O)c(I)c1I</smiles>

Rifamycin SV(IV)<smiles>COC1(OC(C)=O)C=C(I)C(=O)C(I)=C1C</smiles>

Rifamycin O(II)<smiles></smiles>

Rifamycin S(III)

Figure 1(a). Structural relationship between rifamycins B, O, S and SV*.

* The numbering system followed in this text for the rifamycins is that originally used by Prelog et al. ${ }^{10,11}$ to identify the individual carbon atoms and their substituents. This numbering system has been used so far in all literature on the rifamycins. The orientation and numbering system for the rifamycins according to the IUPAC rules is shown in Figure 1(b).

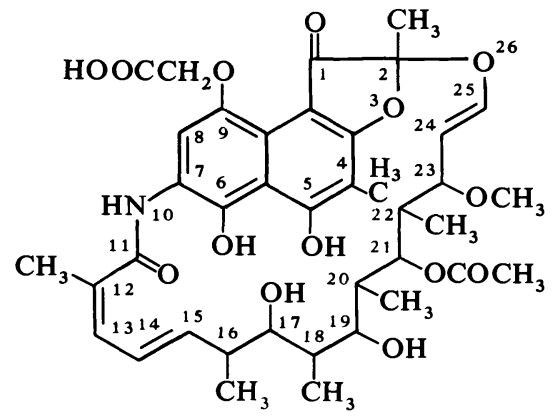

Figure I(b). Numbering systems for rifamycin B according to IUPAC rules.

natural rifamycins, extensive chemical studies on rifamycins $\mathrm{B}, \mathrm{O}$ and $\mathrm{S}$ have yielded several hundred semisynthetic derivatives ${ }^{21-42}$.

The predominant biological activity of rifamycins is their inhibitory effect against Gram-positive bacteria and mycobacteria. Some semi-synthetic rifamycins show also moderate activity against Gram-negative bacteria. Three members of this large group of natural and semi-synthetic antibiotics, namely rifamycin SV, rifamide and rifampicin, are now in clinical use (Figure 2). Rifampicin ${ }^{25,43}$ is a broad-spectrum antibiotic of primary importance in the treatment of tuberculosis ${ }^{44}$. 


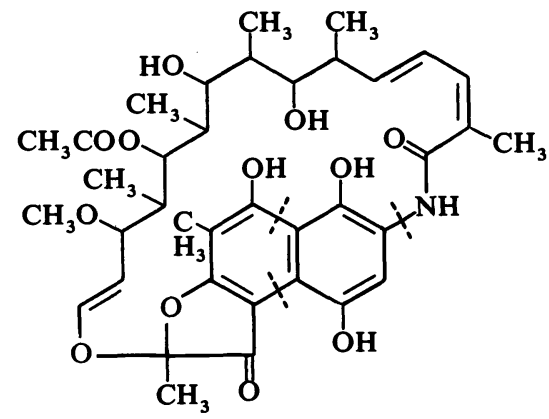

Rifamycin SV<smiles>CCN(CC)CCOc1cc(I)c(O)c(I)c1I</smiles>

Rifamide
Rifampicin

Figure 2. Rifamycins in clinical use.

The rifamycins act on the sensitive bacteria blocking the synthesis of all cellular RNA, because they are potent inhibitors of all bacterial DNAdirected RNA polymerases (DDRP) ${ }^{45-48}$. Most rifamycins are not effective on the mammalian RNA polymerase. Therefore they possess the necessary requisite for ideal chemotherapeutic agents, i.e. a selective toxicity against pathogens. Detailed studies on the mechanism of action of rifamycins revealed that they inhibit the initiation of RNA synthesis, inactivating the enzyme before the incorporation of the first purine nucleotide of the RNA chain $^{46-49}$. Rifamycins form a rather stable equimolecular complex with the bacterial RNA polymerase, binding with the $\beta$ subunit of the enzyme ${ }^{50,51}$.

\section{STRUCTURE-ANTIBACTERIAL ACTIVITY RELATIONSHIPS IN THE RIFAMYCINS}

By making use of the large range of natural and semi-synthetic rifamycins available, it has been possible to derive clear relationships between structural features and antibacterial activity ${ }^{27,52-54}$. The same relationships are valid for inhibition of bacterial RNA polymerase (with the exception of a few rifamycins with strong polar groups, which are unable to cross the bacterial cell wall). In summary, the essential structural requirements for inhibition of bacterial RNA polymerase are: (a) free hydroxy groups on C-21 and C-23 in the ansa chain, (b) hydrogen bond between the functions on C-8 and C-1 in the chromophoric nucleus, (c) a definite spatial relationship between the groups mentioned, shown by the molecular model (Figure 3) based on x-ray crystallographic analysis. In this model the essential functions (a) and (b) lie on the same side of the molecule and are probably the binding sites of the rifamycin with the enzyme.

As the conformation of a molecule in the crystal state does not necessarily indicate the conformation in solution, particularly with a potential flexible structure such as the large ansa chain, the conformation of rifamycin $\mathrm{S}$ was studied by ${ }^{1} \mathrm{H}$-NMR spectroscopy ${ }^{55}$. The similarity of the ${ }^{1} \mathrm{H}$-NMR spectra of rifamycin $S$ in different solvents and at different temperatures strongly suggests the existence of a dominant conformer. 


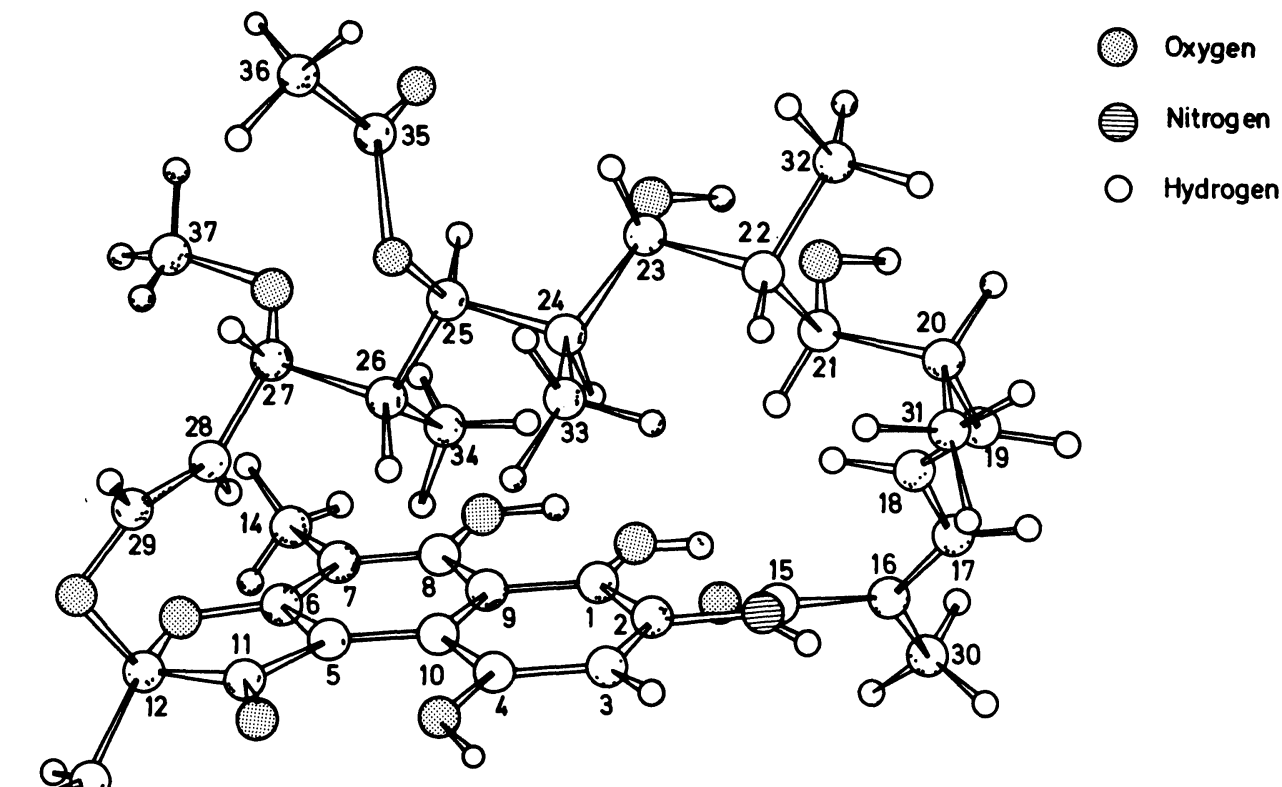

Figure 3. Stereomodel of rifamycin SV.

The nine dihedral angles of the ansa chain from $\mathrm{C}-28$ to $\mathrm{C}-19$, considered conformationally flexible, were obtained from the vicinal interproton coupling constants by the Karplus equation and the proper alternative for each of them compares well with the corresponding values given by solid state $\mathrm{x}$-ray analysis. The possible conformations derivable from the intrinsic alternatives of the n.m.r. method for the ansa chain between C-28 and C-19 are 65536 in number, but if geometrical considerations such as closure of the polygonal path of the ansa and the steric incompatibility between the various atoms of the ansa and of the chromophore were applied, only two of them appeared real. The first corresponds well to that obtained in the solid state by the x-ray method; the second one, although differing from the former in two dihedral angles, leaves practically unchanged the mutual positions of the hydroxy groups at C-23 and C-21.

The various chemical modifications on the chromophoric moiety which leave unaltered the conformation of the ansa, the hydroxy groups at C-21 and $\mathrm{C}-23$ and the hydrogen bond between the substituents on $\mathrm{C}-1$ and $\mathrm{C}-8$, have only a minor effect, positive or negative, on the antibacterial activity of the parent molecule, rifamycin $S$. The variations in activity could be hypothesized to a first approximation as due to variation in the ability of the molecule to penetrate the bacterial cell, correlated with lipophilicity. For this reason, the Hansch approach has been used for a quantitative correlation between the in vitro activity of 76 rifamycins on Staphylococcus aureus and their lipophilicity. A parabolic dependence is observed when all the compounds are considered (Figure 4). 


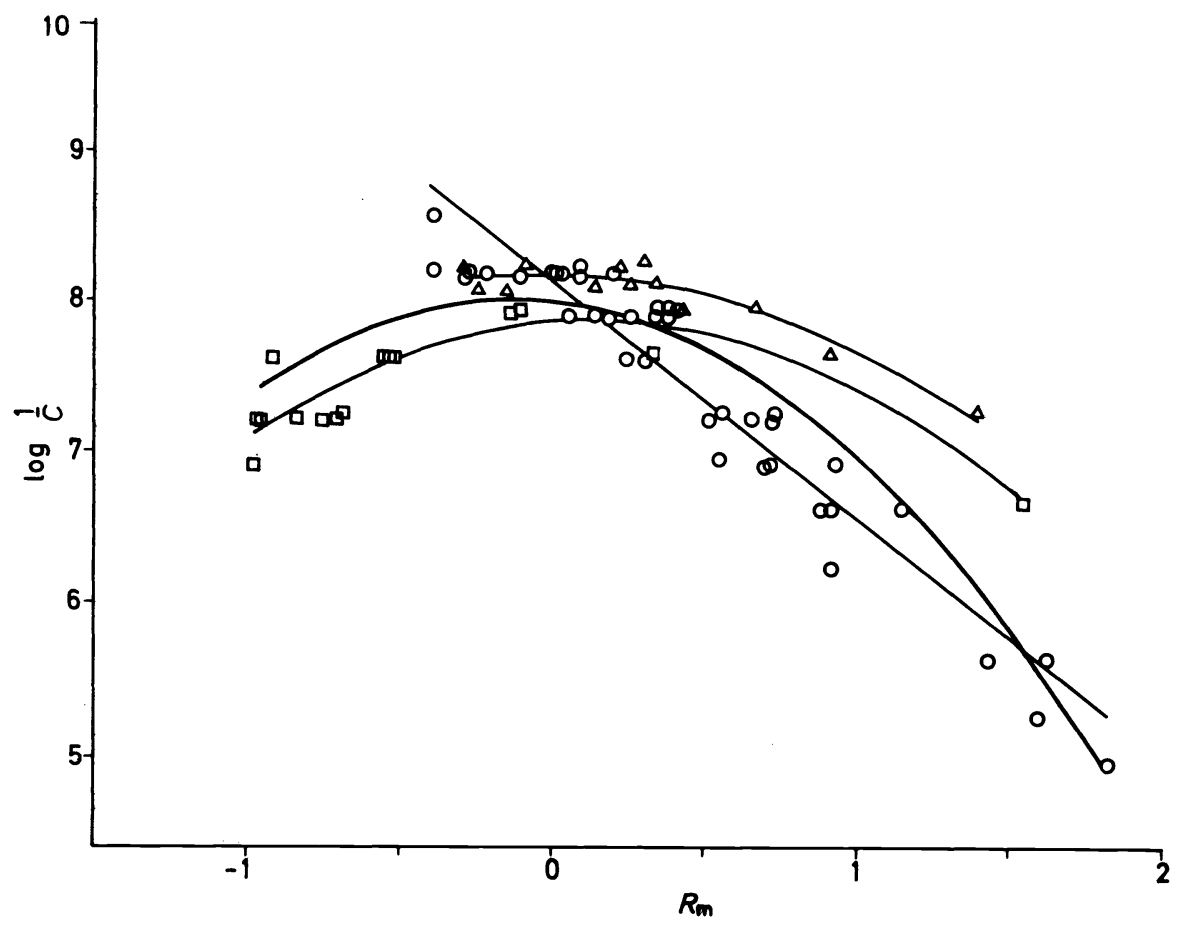

Figure 4. Correlation between activity against $S$. aureus and $R_{\mathrm{m}}$ values: $\bigcirc$ oximes of 3-formyl rifamycin SV; $\square$ amides of rifamycin B; $\triangle$ iminomethylpiperazines of rifamycin $S V$; general.

Although somewhat different curves are obtained when a single series of congeners is examined, the parabolic correlation suggests that it is unlikely that further chemical modification at position 3 and/or 4 would yield new rifamycins more active against $S$. aureus. On the other hand, chemical modifications in the aromatic moiety produce dramatic changes in the pharmacokinetic behaviour of the resulting rifamycins. Rifamycin SV, rifamide and rifampicin have approximately the same activity in vitro against $S$. aureus, but the first two are not significantly adsorbed in the gastrointestinal tract and the third is quantitative adsorbed when administered orally.

\section{OTHER POSSIBLE TARGETS FOR MODIFIED RIFAMYCINS}

The discovery of the inhibitory effect of rifamycins on the bacterial RNA polymerizing enzyme gave rise to the theory that structural modification on the rifamycin molecule could yield products with an inhibitory effect on other RNA or DNA polymerizing enzymes, such as the DNA-directed RNA polymerase (DDRP) of resistant bacteria and of cytoplasmic DNA viruses, and the RNA-directed DNA polymerase (RDDP) of oncogenic RNA viruses.

The DDRP of resistant bacteria became an obvious objective in planning new modified rifamycins with the aim of overcoming the possible decline in 


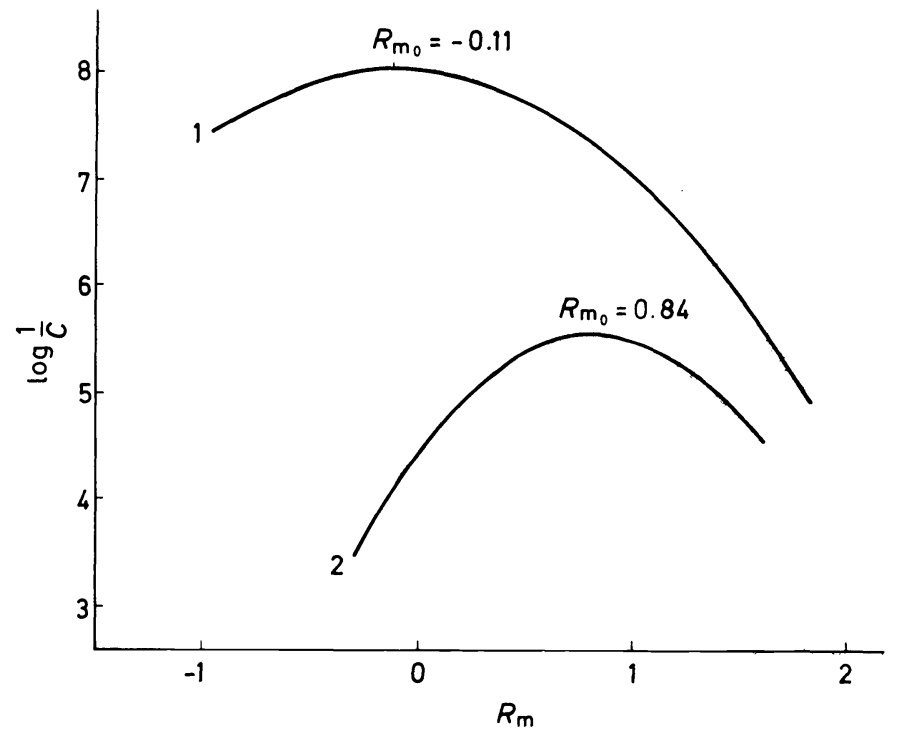

Figure 5. Correlation between activity against $S$. aureus and $R_{\mathrm{m}}$ values: 1 General correlation for sensitive strain; 2 Oximes of 3-formyl rifamycin SV for a rifampicin-resistant strain.

the therapeutic value of these antibiotics as a consequence of the emergence of organisms insensitive to them. In the resistant mutants the $\beta$ subunit of the RNA polymerase is modified and no longer affected by the rifamycins in clinical use ${ }^{57}$.

An intensive chemical study was done with the aim of obtaining rifamycin derivatives active against resistant bacteria. Various oximes and hydrazones of 3-formyl rifamycin SV show, in fact, some activity against a $S$. aureus strain resistant to rifampicin ${ }^{39-42}$. In this case, too, the Hansch approach was considered for prediction of new derivatives ${ }^{56}$ and a parabolic correlation between activity and lipophilicity was obtained (Figure 5). The maximum of activity against the resistant strain is at a higher lipophilic value, but is two orders of magnitude lower than in the case of the sensitive strain.

Further studies on one of the most active compounds, the octyloxime of 3 formylrifamycin SV, have shown that its inhibitory effect on rifamycin insensitive RNA polymerase is due to a non-specific binding to this enzyme, related to its lipophilicity ${ }^{58}$. In fact, it also shows an inhibitory effect on other polymerizing enzymes (for example, the DDRP of mammalian cells ${ }^{59}$ ). The low and non-selective activity on bacterial systems eliminates the possible application of these products as therapeutic agents in the treatment of infections due to micro-organisms resistant to rifampicin.

Also, the DDRP contained in the virions of some large mammalian cyto plasmic DNA viruses, such as pox viruses, has been thought to be a possible target for rifamycins. In fact, rifampicin itself was found to inhibit the growth of pox viruses but its viral inhibitory dose is from 1000 to 10000 times higher than the antibacterial one ${ }^{60,61}$. Attempts to increase the antiviral activity through chemical modification have had only minor success, and no signifi. 


\section{P. SENSI}

cant structure-activity relationship could be derived ${ }^{62}$. It was later discovered that, in contrast to the original assumption, the antivaccinia activity of rifampicin is not related to inhibition of viral polymerase but is due to a block in the virus maturation process ${ }^{63-65}$. In view of all these facts, it can be said that at present there is no real basis for a rational programme of modification of rifamycins for increasing their antiviral activity.

The third area of possible usefulness for rifamycin derivatives is their inhibitory effect on the RDDP, which catalyses the complementary transscription from a polyribonucleotide strand into a polydeoxynucleotide ('reverse transcriptase') ${ }^{66,67}$. This enzymatic activity has been identified in the RNA oncogenic ('oncorna') viruses and also in leukocytes of patients with acute leukaemia. Inhibitors of the reverse transcriptase could constitute a powerful tool for understanding the role of this enzyme in viral carcinogenesis and perhaps could have an inhibitory effect on tumour induction or on tumour growth. The first experiments performed in different laboratories have shown that some rifamycin derivatives were active both on the RDDP of oncogenic viruses ${ }^{68,69}$ and on transformed cells ${ }^{70,71}$. The two effects are not necessarily correlated, and, in fact, rifampicin itself, which is not active against reverse transcriptase, inhibits focus formation by Rous sarcoma virus $^{70}$, probably because it is preferentially toxic to transformed cells ${ }^{72}$.

A large number of rifamycin derivatives were prepared and tested for their inhibitory effect on reverse transcriptase ${ }^{73,74}$. They have been grouped in three classes $(\mathrm{A}, \mathrm{B} \text { and } \mathrm{C})^{75}$, according to their relative inhibitory effect on viral polymerase. The concentrations for $50 \%$ inhibition by these three classes are 5,20 and 100 or more $\mu \mathrm{g} / \mathrm{ml}$, respectively.

Examples of rifamycin derivatives belonging to these classes are: $\mathrm{A}$, rifampicin; rifamycin B: $N, N$-diethylamide sodium salt; 25-desacetylrifamycin B: $N, N$-diethylamide; $3^{\prime}$-carbomethoxy-1',2'-dimethyl-pyrrolo(3.2-0)-4-deoxy-rifamycin SV; B, $N$-demethyl rifampicin; rifamycin SV C, 3-formyl rifamycin SV: $\boldsymbol{O}$-octyloxime; 3-(2,4-dinitrophenylhydrazonomethyl)rifamycin SV; 2,6-dimethyl-4-benzyl-4-demethyl rifampicin. The Class $\mathrm{C}$ rifamycins have a common physicochemical character: a bulky, lipophilic side chain. They inhibit at comparable concentrations several nucleotide polymerases, such as: the calf thymus DDRP ${ }^{59}$ or the DDRP of resistant bacteria ${ }^{58}$.

Therefore, the higher activity against reverse transcriptase is generally associated with a broader spectrum of activity against other transcriptases and with poor selectivity ${ }^{54}$. This could not apply for some of these derivatives. For example, the 3-(2,4-dinitrophenylhydrazonomethyl) rifamycin SV; was indicated as a slightly stronger inhibitor of leukaemic polymerase than of the analogous normal enzyme ${ }^{76}$.

Also, some members of a series of hydrazones of 3-formylrifamycin SV, synthesized by F. M. Thompson et al., have a higher activity against reverse transcriptase than against another nucleotide polymerase, the Escherichia coli DDRP ${ }^{77}$. The ratio is 33 for the $N$-dioctylhydrazone. Whether this ratio is also maintained in comparison with mammalian polymerases has still to be ascertained.

Recently a series of dimeric rifamycins have been synthesized in our laboratory ${ }^{78}$. They, although not lipophilic, are still active against the viral 
RDDP, but their selectivity of action is poor because they are also active against E. coli-resistant DDRP ${ }^{79}$.

Obviously, other studies are necessary for ascertaining the potential value of the rifamycin derivatives prepared so far on oncogenic RNA viruses and on virus-induced tumours. However, from the data at present available, further chemical modifications of rifamycin on the chromophoric moiety do not seem a rational development for obtaining derivatives with selective activity on reverse transcriptase.

It should be emphasized that chemical modifications on this moiety do not affect the above-mentioned structural requisites of rifamycin for binding to the bacterial DDRP. Therefore, the possibility could exist that somewhat different structural requisites are necessary for binding selectively to other nucleotide-polymerizing enzymes. Various different structural features of the ansa and of the chromophoric moiety could be looked for among the variety of natural products synthesized by the ansamycin-producing strains or their mutants, in appropriate conditions.

\section{THE BIOSYNTHETIC APPROACH TO NEW RIFAMYCINS}

A rational approach to new natural rifamycins can derive from the knowledge of the biosynthetic pathway leading from the small molecules constituting the building stones of the complex final molecule. When this knowledge is acquired, experiments can be planned, using appropriate biochemical means or mutants of the original strains, or both, for altering the biosynthetic pathway in order to produce new metabolites.

For example, once it was established that rifamycin B is produced from rifamycin SV, mutants blocked in the last step and therefore accumulating rifamycin SV were looked for and found ${ }^{19}$. Also, when it was discovered that the methyl group on the oxygen in position 27 originated from methionine, the existence of mutant strains unable to perform the methylation was predicted and, in fact, a strain producing the 27-O-demethyl-rifamycin SF was found ${ }^{17}$.

Studies for establishing the origin of all the 37 carbon atoms present in rifamycin $\mathrm{S}$ were performed utilizing the possible precursors labelled with ${ }^{3} \mathrm{H},{ }^{14} \mathrm{C}$ and ${ }^{13} \mathrm{C}$. Experiments feeding the micro-organism with propionic acid labelled with ${ }^{14} \mathrm{C}$ in positions 1,2 or 3 or with ${ }^{14} \mathrm{C}$ in position 1 and ${ }^{3} \mathrm{H}$ in position 3 and systematic degradation of the resulting radioactive rifamycin $\mathrm{S}$ indicated that 23 of the 37 carbon atoms originate from propionic acid $^{80}$.

Studies utilizing ${ }^{13} \mathrm{C}$-labelled propionic acid in positions 1,2 or 3 , and ${ }^{13} \mathrm{C}$-labelled acetic acid in position 1 or 2 , and the examination of carbon magnetic resonance spectra of the resulting samples of rifamycin $\mathrm{S}$ have established the origin of 30 of the 37 carbons present in the antibiotics ${ }^{81-83}$. On the basis of these data, a biogenetic scheme has been suggested ${ }^{81}$ for rifamycin $S$, in which a seven-carbon amino moiety $\left(C_{7} N\right)$ initiates a single polyketide chain composed of eight propionate and two acetate units in the following sequence: 


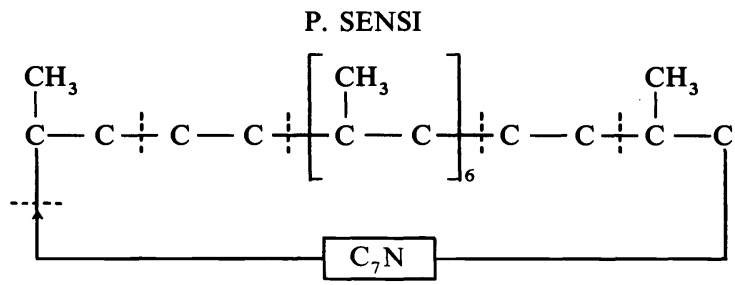

Structural considerations coupled with the results of $\left[{ }^{14} \mathrm{C}\right]$ methyl malonate and $2\left[{ }^{13} \mathrm{C}\right]$ malonate incorporation suggest that all propionate incorporation occurs via methyl malonate and all acetate incorporation via malonate $^{84}$.

The successive biochemical events which yield the final product, rifamycin $\mathrm{S}$, are not known. Two unusual features are the loss of a propionate-derived methyl and the introduction of an ether linkage between two carbons of the same propionate unit:

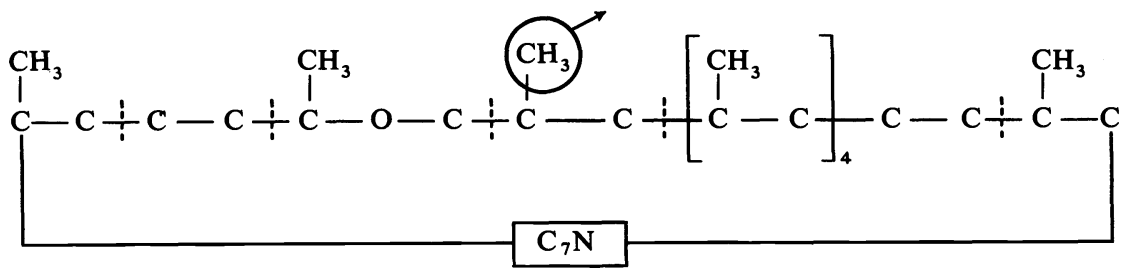

Substitution of the aliphatic bridge occurs after completion of the polyketide chain, the acetoxyl on C-25 deriving from acetate and the methoxyl on $\mathrm{C}_{27}$ from methionine. The comprehensive biogenetic scheme for rifamycin $\mathrm{S}$ is shown in Figure 6.

The scheme for rifamycin biogenesis has been confirmed by the isolation of novel ansamycin, rifamycin $\mathrm{W}$, from a mutant of $N$. mediterranea ${ }^{85}$. Physicochemical studies have established the structure of this compound (Figure 7$)^{86}$, which resembles the hypothetical progenitor. The presence of a hydroxymethyl group in place of the 34a methyl indicates that the methyl loss occurs via the usual oxidative route. Rifamycin W is transformed by the parent Nocardia strain into rifamycin B and is therefore thought to be the normal intermediate in the formation of other rifamycins. The rifamycin biogenetic scheme is immediately applicable to the other ansamycins with naphthalenic chromophore. Therefore, rifamycins, tolypomycin and streptovaricins are thought to derive from a common hypothetical progenitor, as indicated in Figure 8.

The hypothetical common progenitor is thought to undergo a series of modifications, according to the enzymatic characteristics of the producing strains, leading to the final products. Inspecting the structural features of the naphthalenic ansamycins, all the modifications introduced on the common progenitor are schematically summarized in Figure 9. The sequence of the biosynthetic reactions and the substrate specificity of the enzymes involved are not at present known. Assuming, as a working hypothesis, that the various modifications could occur in a non-defined sequence and that the 


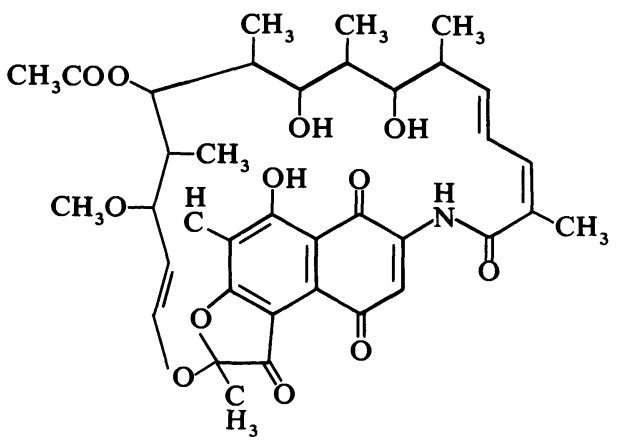

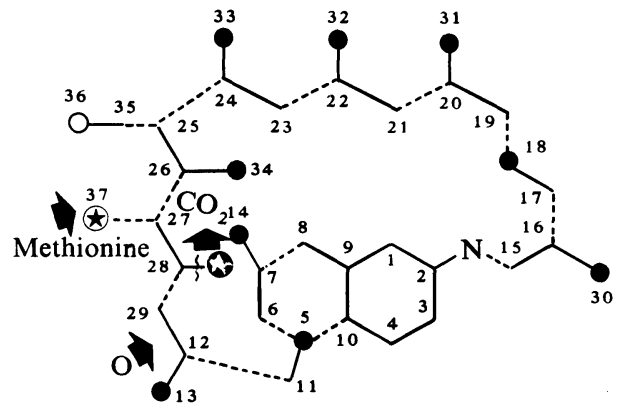

Introduction of oxygen

O- Acetate

Figure 6. Summary of the biogenesis of rifamycin S.

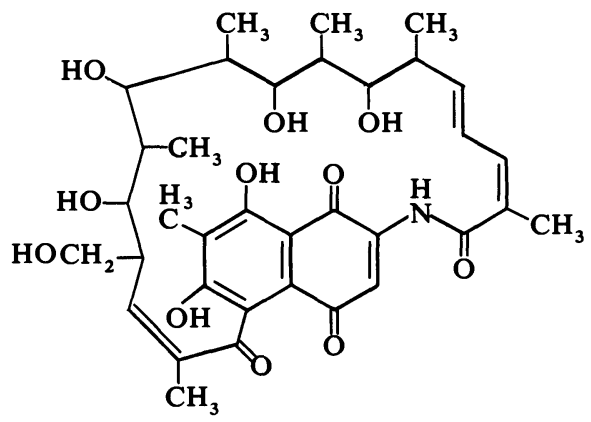

Figure 7. Structural formula of rifamycin W. 


\section{P. SENSI}

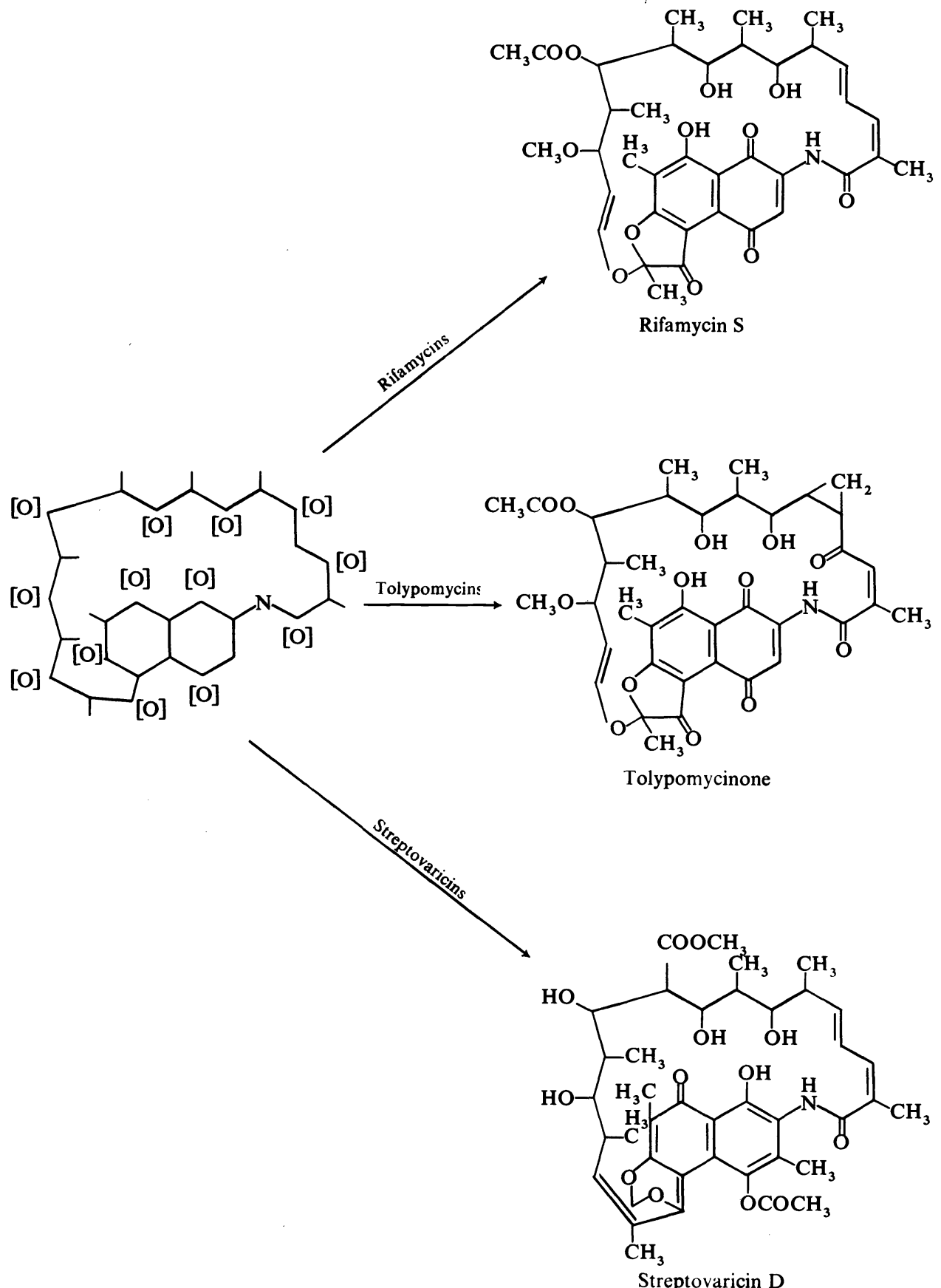

Streptovaricin D

Figure 8. Hypothetical common progenitor of the naphthalenic ansamycins. 


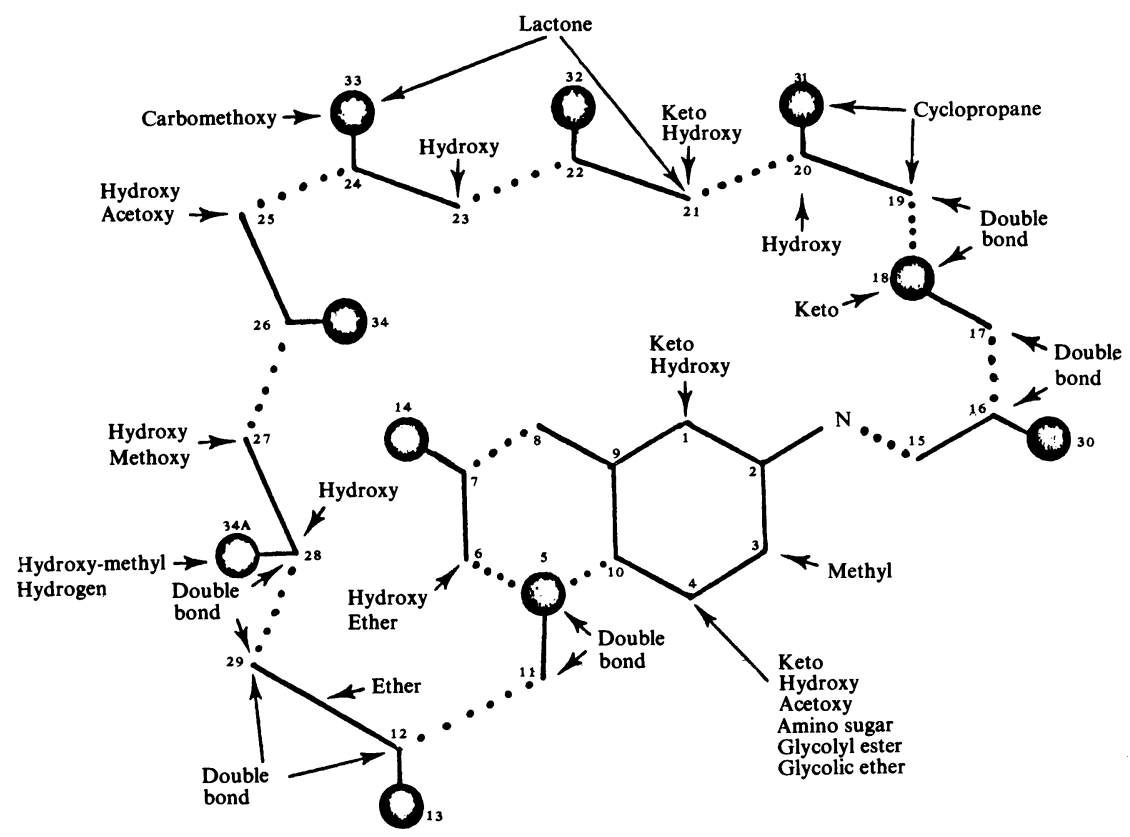

Figure 9. Biosynthetic variants on the primary carbon skeleton of the rifamycins, tolypomycins and streptovaricins.

Table 2. Biosynthetic variants in ansamycins (rifamycins, tolypomycins, streptovaricins)

\begin{tabular}{cccc}
\hline $\begin{array}{l}\text { Carbon atom(s) of } \\
\text { primary C skeleton }\end{array}$ & Variants & $\begin{array}{c}\text { Carbon atom(s) of } \\
\text { primary C skeleton }\end{array}$ & Variants \\
\hline 1,4 & 5 & 33 & 2 \\
3 & 2 & 27 & 2 \\
18 & 2 & 28 & 3 \\
$19(31)$ & 2 & $34 \mathrm{a}$ & 2 \\
20 & 2 & $29(12)$ & 2 \\
21 & 2 & $11(5)$ & 2 \\
25 & 2 & 6 & Total 61440 \\
\hline
\end{tabular}


enzymes involved do not present a rigorous substrate specificity, we have calculated that the combination of all the unknown biosynthetic variants on the primary carbon skeleton could generate 61440 possible natural ansamycins (Table 2). There is no doubt that utilizing different producing strains, their mutants, mixed fermentations and other adequate techniques, a certain number of these possible new ansamycins could become a reality, and experiments along these lines are in progress in our laboratories. Combinations of these variants could hopefully provide the functional groups and the structural conformation required for binding to polymerizing enzymes different from the bacterial DDRP.

\section{ACKNOWLEDGEMENT}

The author thanks Dr E. Terenzi for her assistance in the preparation of the manuscript.

\section{REFERENCES}

1 A. Lüttringhaus and H. Gralheer, Liebigs Ann. Chem. 550, 67 (1942).

2 V. Prelog and W. Oppolzer, Helv. Chim. Acta, 56, 2279 (1973).

${ }^{3}$ P. Sensi, P. Margalith and M. T. Timbal, Farmaco, Ed. Sci. 14, 146 (1959).

4 P. Margalith and G. Beretta, Mycopathol, Mycol. Appl. 13, 321 (1960).

5 J. E. Thiemann, G. Zucco and G. Pelizza, Arch. Mikrobiol. 67, 147 (1969).

6 P. Sensi, A. M. Greco and R. Ballotta, Antibiotics Ann. 262 (1959).

P. Margalith and H. Pagani, Appl. Microbiol. 9, 325 (1961).

8 P. Sensi, R. Ballotta and G. G. Gallo, Farmaco, Ed. Sci. 16, 165 (1961).

9 P. Sensi, M. T. Timbal and G. Maffii, Experientia, 16, 412 (1960).

10 W. Oppolzer, V. Prelog and P. Sensi, Experientia, 20, 336 (1964).

11 W. Oppolzer and V. Prelog, Helv. Chim. Acta, 56, 2287 (1973).

12 M. Brufani, W. Fedeli, G. Giacomello and A. Vaciago, Experientia, 20, 339 (1964).

${ }_{13}$ N. Bergamini and G. Fowst, Arzneim.-Forsch. (Drug. Res.) 15, 951 (1965).

${ }_{14}$ K. Leitich, V. Prelog and P. Sensi, Experientia, 23, 505 (1967).

15 M. Brufani, W. Fedeli, G. Giacomello,and A. Vaciago, Experientia, 23, 508 (1967).

16 G. C. Lancini, G. G. Gallo, G. Sartori and P. Sensi, J. Antibiotics, 22, 369 (1969).

17 G. C. Lancini, C. Hengeller and P. Sensi, in Progress in Antimicrobial and Anticancer Chemotherapy, Vol. I, p 1166. University of Tokyo Press; Tokyo (1970).

18 S. Sugawara, K. Karasawa, M. Watanabe and T. Hidaka, J. Antibiotics, 17, 29 (1964).

19 G. C. Lancini and C. Hengeller, J. Antibiotics, 22, 637 (1969).

20 J. Birner, P. R. Hodgson, W. R. Lane and E. H. Baxter, J. Antibiotics, 25, 356 (1972).

21 A. M. Greco, R. Ballotta and P. Sensi, Farmaco, Ed. Sci. 16, 755 (1961).

22 P. Sensi, M. T. Timbal and A. M. Greco, Antib. Chemotherapy, 12, 488 (1968).

23 P. Sensi, N. Maggi, R. Ballotta, F. Furesz, R. Pallanza and V. Arioli, J. Med. Chem. 7, 596 (1964).

24 N. Maggi, V. Arioli and P. Sensi, J. Med. Chem. 8, 790 (1965).

25 N. Maggi, R. Pallanza and P. Sensi, Antimicrobial Agents and Chemoth. 765 (1965).

26 S. Furesz, V: Arioli and R. Pallanza, Antimicrobial Agents and Chemoth. 770 (1965).

27 P. Sensi, N. Maggi, S. Furesz and G. Maffii, Antimicrobial Agents and Chemoth. 699 (1966).

${ }^{28}$ H. Bickel, F. Knusel, W. Kump and L. Neipp, Antimicrobial Agents and Chemoth. 352 (1966).

29 G. G. Gallo, C. R. Pasqualucci, N. Maggi, R. Ballotta and P. Sensi, Farmaco, Ed. Sci. 21, 68 (1966).

30 N. Maggi and R. Pallanza, Farmaco, Ed. Pr. 22, 307 (1967).

31 N. Maggi, A. Vigevani, G. G. Gallo and C. R. Pasqualucci, J. Med. Chem. 11, 936 (1968).

32 N. Maggi, A. Vigevani and R. Pallanza, Experientia, 24, 209 (1968).

${ }^{33}$ F. Knusel, H. Bickel and W. Kump, Experientia, 25, 1207 (1969).

34 N. Maggi, V. Arioli and G. Tamborini, Farmaco, Ed. Sci. 24, 263 (1969).

35 R. Cricchio and G. Tamborini, J. Med. Chem. 14, 721 (1971). 


\section{RECENT PROGRESS IN THE CHEMISTRY AND BIOCHEMISTRY OF RIFAMYCINS}

36 R. Cricchio, G. Tamborini, P. Bravo and G. Gaudiano, Farmaco, Ed. Sci. 29, 358 (1974).

37 W. Kump and H. Bickel, Helv. Chim. Acta, 56, 2323 (1973).

38 W. Kump and H. Bickel, Helv. Chim. Acta, 56, 2348 (1973).

39 R. Cricchio, G. Lancini, G. Tamborini and P. Sensi, J. Med. Chem. 17, 396 (1974).

40 R. Cricchio, V. Arioli and G. Lancini, Farmaco, Ed. Sci. in press.

41 R. Cricchio, G. Cietto, E. Rossi and V. Arioli, Farmaco, Ed. Sci. in press.

42 R. Cricchio, G. Carniti, G. Cietto, G. Tamborini and V. Arioli, Farmaco, Ed. Sci. in press.

43 N. Maggi, C. R. Pasqualucci, R. Ballotta and P. Sensi, Chemotherapy, 11, 285 (1966).

44 G. Binda, E. Domenichini, A. Gottardi, B. Orlandi, E. Ortelli, B. Pacini and G. Fowst, Arzneim.-Forsch. (Drug. Res.) 21, 1907 (1971).

45 G. Hartmann, K. O. Honikel, F. Knusel and J. Nuesch, Biochem. Biophys. Acta, 145, 843 (1967).

46 H. Umezawa, S. Mizuno, H. Yamazaki and K. Nitta, J. Antibiotics, 21, 234 (1968).

47 G. C. Lancini and G. Sartori, Experientia, 24, 1105 (1968).

48 G. C. Lancini, R. Pallanza and L. Silvestri, J. Bacteriol. 97, 761 (1969).

49 A. Sippel and G. Hartmann, Biochem. Biophys. Acta, 157, 218 (1968).

50 W. Wehrli, K. Knusel, K. Schmidt and M. Staehelin, Proc. Nat. Acad. Sci. USA, 61, 667 (1968).

51 W. Wehrli and M. Staehelin, Biochem. Biophys. Acta, 182, 24 (1969).

52 W. Wehrli and M. Staehelin, Bact. Reviews, 35, 290 (1971).

${ }^{53}$ S. Riva and L. G. Silvestri, Ann. Rev. Microbiol. 26, 199 (1972).

54 P. Sensi, Pure Appl. Chem. 35, 383 (1973).

55 G. G. Gallo, E. Martinelli, V. Pagani and P. Sensi, Tetrahedron, 30, 3093 (1974).

56 G. Pelizza, G. C. Lancini. G. C. Allievi and G. G. Gallo, Farmaco, Ed. Sci. 28, 298 (1973).

57 D. Rabussay and W. Zillig, FEBS Letters, 5, 104 (1969).

58 S. Riva, A. Fietta and L. G. Silvestri, Biochem. Biophys. Res. Commun. 49, 1263 (1972).

59 M. Meilhac, Z. Tysper and P. Chambon, Europ. J. Biochem. 28, 291 (1972).

60 E. Heller, M. Argamon, H. Levy and N. Goldblum, Nature, 222, 273 (1969).

61 J. H. Suback-Sharpe, M. C. Timbury and J. F. Williams, Nature, 222, 341 (1969).

62 B. Moss, E. N. Rosenblum, P. M. Grimley and S. J. Mirus, Antimicrobial Agents and Chemoth. 181 (1972).

63 T. H. Pennington, E. A. Follett and J. F. Szilagyi, J. Gen. Virol. 9, 225 (1970).

64 B. Moss, E. N. Rosemblum and P. M. Grimley, Virology, 45, 123 (1971).

65 B. Moss, E. N. Rosemblum and P. M. Grimley, Virology, 45, 135 (1971).

66 H. M. Temin and S. Mizutani, Nature, 226, 1211 (1970).

67 D. Baltimore, Nature, 226, 1209 (1970).

68 C. Gurgo, R. K. Kay, L. Thiry and M. Green, Nature, 229, 111 (1971).

69 R. C. Gallo, Nature, 234, 194 (1971).

${ }^{70}$ H. Diggelman and C. Weissman, Nature, 224, 1277 (1969).

${ }^{71}$ M. Calvin, U. R. Joss, A. J. Hackett and R. B. Owens, Proc. Nat. Acad. Sci. USA, 68, 1441 (1971).

72 A. Vaheri and H. Hanafusa, Cancer Res. 31, 2032 (1971).

73 R. S. Yang, F. Herrera, R. G. Smith, M. Reitz, G. C. Lancini, R. C. Ting and R. C. Gallo, J. Nat. Cancer Inst. 49, 7 (1972).

74 C. Gurgo, R. Ray and M. Green, J. Nat. Cancer Inst. 49, 61 (1972).

75 R. C. Ting, S. S. Yang and R. C. Gallo, Nature New Biol. 236, 163 (1972).

76 R. G. Smith, J. Wang-Peng, R. C. Gallo, P. Levine and R. C. Ting, Nature New Biol. 236, 166 (1972).

${ }^{77}$ F. M. Thompson, A. N. Tischler, J. Adams and M. Calvin, Proc. Nat. Acad. Sci. USA, 7, 107 (1974).

78 R.Cricchio et al., paper in preparation.

79 A. M. Fietta and L. G. Silvestri, in press.

80 M. Brufani, D. Kluepfel, G. C. Lancini, J. Leitich, A. S. Mesentsev, V. Prelog, F. P. Schmook and P. Sensi, Helv. Chim. Acta, 56, 2315 (1973).

81 R. J. White, E. Martinelli, G. G. Gallo, G. Lancini and P. J. Beynon, Nature, 243, 273 (1973).

82 E. Martinelli, R. J. White, G. G. Gallo and P. J. Beynon, Tetrahedron, 29, 3441 (1973).

83 E. Martinelli, R. J. White, G. G. Gallo and P. J. Beynon, Tetrahedron Letters, 15, 1367 (1974).

84 A. Karlsson, G. Sartori and R. J. White, Europ. J. Biochem., 47, 251 (1974).

${ }^{85}$ R. J. White, E. Martinelli and G. C. Lancini, Proc. Nat. Acad. Sci. USA, 71, 3260 (1974).

86 E. Martinelli, G. G. Gallo, P. Antonini and R. J. White, Tetrahedron, 30, 3087 (1974). 